\title{
A Few Implementation Solutions for Business Intelligence
}

\author{
Manole VELICANU \\ Academy of Economic Studies, Bucharest, România \\ Gheorghe MATEI, Romanian Commercial Bank
}

To succeed in the context of a global and dynamic economic environment, the companies must use all the information they have, as efficiently as possible, in order to gain competitive advantages and to consolidate their position on the market. They have to respond quickly to the changes in the business environment and to adapt themselves to the market's requirements. To achieve these goals, the companies must use modern informatics technologies for data acquiring, storing, accessing and analyzing. These technologies are to be integrated into innovative solutions, such as Business Intelligence systems, which can help managers to better control the business practices and processes, to improve the company's performance and to conserve it's competitive advantages.

Keywords: Business Intelligence, competitive advantage, OLAP, data mining, key performance indicators.

$\mathbf{1}^{\mathrm{I}}$ Introduction

In today's context of a competitive economic environment which is permanently changing, the ability to use intelligent information in order to cope with the challenges and to benefit for the opportunities represents an essential condition for any company that wants not only to stay on the market, but also to consolidate its position. In any organization, there is a large volume of data concerning production indicators, financial reports, data about sales, balance sheets, forecasts etc. In spite of this, the managers are frequently missing information of high quality, timely updated, in order to make the best decisions. To remain competitive in the global competitive economy, companies have to adapt themselves to any action of the market, to respond dynamically to the changes in the business environment and customers' requirements. Moreover, they have to anticipate the changes inside and outside the industry they are acting in and quickly make the adequate decisions. Making fast business decisions, based on reliable information, is essential for any company. That is why they must have proper instruments to intercept immediately the changes in the economic, social, legislative and administrative environment, to analyze them and to make the proper decisions as soon as possible. Companies must permanently know which are the most highly demanded products on the market, which are the most profitable customers, what new products and services they should provide if they want to stay efficient. Beside competitiveness, companies must permanently be concerned with the optimization of their value chains and the enhancement of the decision process. For achieving these goals, they must implement some solutions, which are capable to offer management an overview of the organization at a certain moment, as well as projections on different periods. Such solutions must be capable to assist the decision process in order to make coherent and well based strategies. These solutions must provide answers to "what-if" questions and to find patterns to guide strategic decisions making.

\section{The role and goals of Business Intelli- gence}

These goals cannot be achieved without the help of information technologies, especially Business Intelligence solutions. This term was proposed in 1989 by Howard Dresner who, at that time, was a researcher at Gartner Group. He defined Business Intelligence as "a set of concepts and methods for improving the decision process, using support systems based on facts".

Business Intelligence (BI) is an information technology dealing with the structure, func- 
tioning and management of organizations, by using the computational technique. The success of a company relies on information. BI is a systematic process of collecting, analyzing and disseminating information. That sets to achieve or conserve competitive advantages, preventing deviations in the company's activity and grabbing the opportunities on the market. BI consists of a set of applications and technologies for data storing, accessing and analyzing, in order to help users make better decisions.

In the article [VELU06] more goals of BI are presented, among which we can mention:

- providing business solutions at law costs, which can give advantages to the company;

- easy and fast data access for numerous and diverse users;

- providing the technological support for data analyses;

- building a collaborative environment;

- providing an open and scalable framework.

These solutions enable the intelligent usage and interpretation of business information. With their help, the users can better control the business practices and processes and analyze the performance indicators. Decisions are more efficient if the information about the business environment and competitors are analyzed with such applications, which provide capabilities of extrapolation and making correct forecasts concerning the future economic trends and conditions. They offer companies and users on all the hierarchical levels a solid, complete and powerful technology for extracting, from a large volume of data, the key information, relevant and useful for decision process and business control.

Knowing all the aspects of the business and understanding both the factors having a positive influence and, especially, those having a negative impact, represents an important requirement for performance improvement and company's increase on the market. By using the new information technologies, the companies learn what has happened in their business, why it has happened and what will happen. All these things, together with the users' experience and intuition, lead to gaining competitive advantages [VEMA07a]. At the same time, BI solutions contribute to the elimination of communication barriers inside the company and enable decisions making on the basis of consistent information and collaborative support.

Thus, BI has a crucial role in consolidating the company's position on the market, implementing the best practices and improving the business processes, and helping the company become more competitive and efficient. Nowadays, the company's performance depends more and more on the level of adaptation of the information systems to the general purposes of the organization. A powerful BI platform ensures fast data access and provides capabilities of performance analyses, getting synthetic information concerning both its own business and competitors' business. It aims to improve the quality of information concerning:

- market conditions and future trends;

- company's position in comparison to the one of its competitors;

- company's capabilities;

- the social, legislative and political environment;

- how other companies operate on the market;

- changes in customers' behavior etc.

On the basis of this information companies can decide on the proper measures for the necessary adjustments in order to conserve and extend its position on the market.

The concept of BI originates from the executive information systems in the early 1990s. The BI systems are composed of more instruments which allow to access the relevant information of the organization and to present it in a meaningful form. Their purpose is to achieve competent analyses concerning the company's activity, and to turn the information into knowledge that can help the decision process, so that the decided actions contribute to the organization's success. More and more managers of the business environment think that $\mathrm{BI}$ has become a vital instrument meant to help the company to achieve strategic goals, performance enhancement and improve the decisions and the 
strategic development plans.

The worldwide market of the BI solutions is raising significantly. A survey made by Gartner Group in 2006 on a sample of 1400 companies found that BI area was considered the first technological priority. This year, the revenues from selling BI licenses were estimated at $\$ 2.5$ billion, with $6 \%$ more than in the previous year [GART06]. For the first time, BI has become the leader in the technological priorities of the organizations, instead of the information security which held this position for years.

In 2009, worldwide BI sales will total $\$ 3$ billion, with an average annual growth rate of $7.3 \%$. While the growing in the developed countries will be between $6.3-6.9 \%$, on the emergent markets it will be between 11.3 $11.6 \%$ yearly.

\section{Business Intelligence contribution to the business processes improvement}

The optimization and automatization of the business process by the help of BI systems contribute to the enhancement of the decision system, and offer a global view of the entire activity. BI solutions are present in all domains. Most of them include financial analyses, analysis of current and potential customers, sales and marketing campaign efficiency etc. They contribute to attracting customers and to making them loyal, and to building a long term partnership, a better management of their requirements, the identification of new customer and product segments, fraud detection and operational risk management. A study conducted by Europe VISA in 2005, based on the monitoring of seven European banks which issue Visa cards, found that the usage of BI solutions has reduced frauds from 4576 to 458 cases monthly, also substantially decreasing the number of false alarms.

By using all data at their disposal, through their complex analyses, the company gets new and valuable information concerning the business environment and the competition. This information help the company to better understand the consumers' behavior and to meet their requirements, to properly manage the threats and risks, to identify the opportunities for income increase and cost decrease. Gathering and storing large volumes of historical data make discovering of patterns and factors that are influencing the company's activity and making predictions about the business future trend possible. Selecting the relevant information, analyzing and structuring them is difficult without BI systems, and the results are often incomplete or late. Companies using BI technologies have the greatest chances successfully coping with all the challenges of the competitive environment.

Without these solutions, the essential information remains hidden in the continuous increasing data volume that is permanently accumulated in the company. Without instruments capable to analyze these data in a better way, the identification of market trends, the forecasting of the future evolution, establishing the necessary strategies remain much more intuitive than based on pertinent analyses. Moreover, the results of these intuitive analyses cannot be timely obtained, and obtaining them later makes them less relevant. Turning information into a strategic resource represents one of the managers' major problems. Through its capability of providing the necessary information for continuing to stay on an extremely competitive market, BI becomes a principal attribute of the strategy of more and more companies.

As time passes, companies gather an ever larger data volume. The transactional systems and the classical database solutions do not provide the necessary support for complex analyses. They are developed for the operational activities of the company, while the BI solutions are developed for improving the analysis process. The information are integrated and organized in structures that respond to the requirements of complex data analyses, reporting and forecasting, in order to make the best decisions, to achieve efficient activities and to obtain consistent results.

Not long ago, only some departments in a company were using BI applications. This situation is rapidly changing, by developing and acquiring systems that cover all of the 
company's functions. The new systems extend the BI's advantages to all participants to the business: employees, shareholders, customers, providers and other business partners. This way, making the information available for all the interested users, an information democracy is established in the entire company and even outside the company.

The most important factors that influence the BI are: the customers, the competitors, the business partners, the economic environment and the internal operations [WIKI06].

The customers represent the most important problem in ensuring the company's success. The company has no purpose without its customers. The new worldwide economic context focuses on customers. That's why it is very important for the company to have current information about customers' preferences. The company must be capable to adapt quickly at the changes in customers' requirements. The BI enables the acquisition of information concerning market evolution and provides directions of action for creating innovative and high quality products and services, that anticipate future customers' requirements.

The competitors can be an important obstacle on the way to success. Their aims are the same with those of the company's, that is to maximize profit and increase customer satisfaction. In order to be succesful, the company has to be one step ahead of its competitors. The BI provides valuable information concerning the competitors' actions, so that fully aware decisions could be made.

The business partners have to dispose of the same strategic information, in order not to have problems of communication which can produce disfunctionalities. It is common for a company to enable its providers to view its inventories and other information of common interest, in order to improve the supply chain management. With the BI systems the company can share the information with its business partners.

The economic environment, such as the economy's state and other key indicators, weights significantly in making business decisions. Nobody wants to launch new prod- ucts during an economic recession. The BI provides information about the economic conditions so that managers can make prudent decisions concerning the most suitable moment for business expansion or contraction.

The internal operations are activities, which occur daily in the company. The decision makers must have deep knowledge about the entire company's activity. It is possible to have negative results for the business if the decisions are made without knowing the entire activity.

The BI systems are pursuing a better understanding of the business processes that take place in the company. To achieve this purpose they are turning the data from various sources into useful information. Then the information are turned into knowledge that is used to decide the actions to succeed. The actions undertaken produce new data and information, which are used to enrich the knowledge and to improve the business processes.

\section{Business Intelligence technologies}

The BI solutions use various applications and technologies to gather, store, access, analyze and deliver the data in an easy and useful manner. These products facilitate the business performance management and help in making better decisions, providing on time up to date, reliable and relevant information. The BI systems are integrated systems, which comprise in their architecture some of the most advanced information technologies: data warehouse, ETL (Extract, Transform, Load) and EAI (Enterprise Application Integration) instruments, OLAP (On Line Analytical Processing) and data mining tools, are some examples of technologies capable to provide integration, storing, analyzing and reporting functions. They have to cover the whole process of turning data into information and knowledge: data gathering, cleansing, integration and storing, predictive analyses, querying and reporting. On the other hand, these systems are open to the new technologies that can be developed.

The data warehouse concept represents a 
logical architectural approach for extracting the operational data and turning them into accurate historical information, in order to help the decision process. The data warehouse technology enables the integrating and the storing of large data volumes, both from internal and external sources. The fundamental criterion for data organization in a data warehouse is the subject (the business line). The purpose of such a system is to provide to the analysts an integrated and consistent view over the relevant data of the organization.

The development of a data warehouse represents a complex process that involves more activities, depending on the used working methodology, from the identification of the users' requirements to the deployment of the system [VEMA07c]. The data warehouse development has to be thought of as a continuous process, which is evolving at sink with the organization. On the basis of the data systematized and consolidated in such repositories, the analysts can make complex analyses concerning the company's performance, can identify various correlations among data, trends for estimating the future evolution, as well as solutions for improving the carried out activities [VEMA07b].

OLAP is an essential component of a BI platform, the most used analysis method. Making complex analyses of historical data, the OLAP instruments enable the identification of meaningful trends. By understanding the factors that influence the business processes and by extrapolating the identified trends, the decidents can establish the most adequate strategies for the company's development.

An OLAP instrument is a combination of analytical processing procedures and graphic presentation (the user's interface). OLAP instruments enable complex computations and provide users with the possibility to access and analyse large data volumes, the relations among them, and to present the data from various views (a multidimensional outlook of data). They provide the possibility of complex analyses, such as time series, graphs, extrapolations, statistical analyses and whatif analyses. The analytical processing proce- dures are methods for the identification of the information needed in the decision process. The interfaces that are used are based on the multidimensional presentation of the data and enable their fast and interactive analysis through particular operations as drill-down, roll-up, slice, dice and pivoting. These operations enable the users to see the data in many ways, from various views, without the need of requiring them.

Data mining represents the activity of data extracting and analyzing for discovering information that are hidden or more difficult to be observed with other instruments. With the help of this technology, relations and correlations can be identified among certain data or data sets. Data mining instruments enable the users to explore and analyze large data volume, in order to discover patterns, rules and trends, by using statistical, mathematical and forms recognition techniques.

Data mining is a technology that uses complex algorithms for data analyzing and discovering valuable information for the decision makers and analysts. Thus, special algorithms are used, such as fuzzy logic, neural networks, induction, clustering, that correlate the information from the data warehouse and support the analysis and decision process. By means of statistical analysis or artificial intelligence methods, the data mining techniques enable the users to identify patterns, rules and correlations among data and to create predictive models which can anticipate behaviors or events on the basis of the trends highlighted in the data.

OLAP technology provides analyses based on models, having a retrospective nature, and the user must understand how to explore the data. Data mining has a prospective nature and provides analyses based on data. The information says something about itself without asking any question. While OLAP organizes the data into a model built in order to be explored by analysts, data mining analyses the data in order to provide useful information for forecasting and making decisions. Thus, the analysts can discover data correlations that are hidden or too complex to be identified by means of the common statistical 
techniques.

OLAP, data mining and data warehouse technologies cooperate with each other. They provide the information in a flexible, interactive and consistent manner, turning the huge data volume stored in the data warehouse into useful information for the decision makers. $\mathrm{BI}$ is a concept which brings important changes for the companies, on the basis of international standards and best practices, with major implications on the information system, but also on the organizational structure, the institutional culture and the business processes. Some of its advantages are:

- increasing the usage of systems and information;

- decreasing the efforts for realizing the administrative tasks;

- the growth of labor productivity;

- providing high quality, homogeneous and coherent data;

- building and developing advanced platforms for information reporting and management;

- the management and the integration of data models;

- the possibility of defining multiple business rules and tracking their compliance at every hierarchical level;

- monitoring the results, highlighting the trends, the threats and opportunities;

- analysing performances against the goals established in order to make possible to take measures for timely adopting the strategies to the current conditions;

- fast response to market changes, anticipating them and their impact on the business;

- helping the decision process and adopting proactive managerial actions.

A BI solution does not contain only one application, but a set of software components that interact in order to extract the data from the source systems, to clean, integrate and store them in a single and consistent manner, to make complex analyses and to provide the results in time, in an aggregated and understandable manner.

The software components of a BI solution can be classified into the following categories: for data extracting and transforming, for data cleansing, for data loading and refreshing, for data accessing, for ensuring data security, for version control and configuration management, for data backup and recovery, for performance monitoring, for platform management, for data modeling, for metadata management [VEMA07d].

Through the BI solutions, the available data contribute to the increasing of the value added within the company and to improve the relationships with the customers and providers. BI enables a more accurate understanding of the current situation and provides a global view of the company's performances. Therefore, these systems represent the mechanism for turning data into decisions of acting. Nowadays, in the conditions of an increasingly more global, competitive, complex and dynamic economy, the implementation of a BI solution tends to provide more than a competitive advantage and becomes more and more of a condition to survive on the market. On the other hand, the capability to realize predictive analyses makes possible a fast return of investments made in BI systems. They enable the company to forecast and manage correctly the customers' requirements and not only to react to them, and contribute to the revenues growth. In the same time, several ways for effective reducing the costs can be established on the basis of predictive analyses. Otherwise, the costs reducing within a company's area may induce their growing within another area, with negative impact on the global profit.

\section{Business Intelligence - an instrument for assisting the decision process}

A BI system is structured on three levels: the operational reporting level, the analyzing and modeling level and the strategic level. The operational level is based on the concept of management through objectives, exceptions and facts, according to which a manager must permanently know the status of the business process in comparison to the objectives established and to be informed when any deviation appears, in order to be able to make the proper decisions at the right time. The analyzing level assists the area of bud- 
geting, reporting, financial analysis, cost analysis on activities, and at the strategic level the company's strategy and mission are formulated, the strategic indicators are monitored, as well as the cause-effect relationship among them.

For supporting such a system, from the information point of view, data warehousing solutions are used for transactional data consolidation and reconciliation. Beside these solutions, more applications and instruments were developed to process this information and provide the possibility tof realize complex analyses concerning the company's activity.

The BI systems ensure:

- provision of high quality information to all the users, at the right time;

- performance evaluation and exceptions identification;

- forecasts based on plans and results that are permanently updated.

BI ensures key analyses for all the functional domains of the company: finance, production, procurement, supply, marketing, human resources. By its help, it is possible to make [MICR04]:

- Marketing analyses, which use information about customers, and sales, price sensitivity and the favorites products. The usage of this information leads to a better planning of the marketing campaigns and to the determining of their efficiency.

- Sale analyses, through which trends are discovered, seasonality is analyzed, and associations among groups of customers and products are made. This information contributes to settle the sale targets and to analyze the acquired results.

- Supply chain analyses, by tracking the data concerning the orders, deliveries and inventories. Thus, a better inventory planning can be realized, the most proper price promotion and the delivery schedule can be established.

- Scorecard applications, which define key performance indicators computed on the base of the information from the existing systems. The company's global performance or the performance as in comparison to other similar entities can be tracked by means of these applications.

- Financial analyses, which can determine the efficiency of every department, category of products, geographical regions or seasons. The financial institutions (banks, assurance or leasing companies) represent the most eloquent example for the key role that financial analysis plays in the company's activity: defining the products and services, loan portfolio analysis etc.

- Budget planning that provides different variants and supports the choice of the best solution.

- Support and customer relationship centers, which enable to analyze the rate of telemarketing campaigns' success, the customers' complaints, the incidents that have occurred etc.

- Geospatial analyses that combine business information with geographical and demographic information in order to identify patterns and trends.

- Project management analyses, that analyse the project portfolio, the resource allocation and the meeting of the deadlines.

To make the best decisions, the information must be included in an updating, processing and analyzing flow. To increase the business performance, today's managers need complete information that integrates transactional applications such as ERP (Enterprise Resource Planning), CRM (Customer Relationship Management) and SCM (Supply Chain Management) with BI applications and instruments that enable the analyses of the daily activity, the comparison of the achieved performance with the organization's strategy, as well as a better administration of the entire management process.

The usage of the BI systems provides the company's management with both an instrument for assisting the decision process and a performance control tool.

The need for managerial reporting and complex analyses represents an important requirement for any company that acts in a competitive environment. Starting from the complex reports provided by the BI solutions, the deficient processes can be identified and corrected and even the logic of some 
activities' carrying out can be changed in order to respond to the company's performance and efficiency requirements. BI is no longer just an option, an in vogue solution. It has become a necessary and mandatory solution at every organizational level of the companies that want to get relevant information and knowledge concerning the business environment they act in. The purpose is to preserve and improve their position in a competitive and increasingly more aggressive environment with faster and faster information flows.

BI systems filter the information and delivery them in a customized way to those who need them. Each user has the right to access only the information he needs, depending on his professional responsibilities and competences. Thus, a general manager may use a dashboard with the most important indicators concerning the company's activity; financial statistics and analyses can be realized in the financial and accounting department; analyses concerning the customers, their preferences and the actions that can lead to their loyalty are made in the marketing department; the level of customers' content concerning the company's products and services can be measured in a call center and so forth. BI systems provide many advantages to the companies which use them. They provide the possibility to make decisions based on accurate and actual information, leading to global performance improving. They also limit the work based on intuition, contribute to the improvement of the communication among departments and to the coordination of the activities, and they enable companies to respond faster to the changes of the financial conditions, customers' preferences, supply chains etc.

\section{Conclusions}

In conclusion, we can state that Business Intelligence represents the ability of gaining competitive advantages by judiciously exploring information. BI is a management, controlling, analyzing, reporting and forecasting system. Analyzing large data volumes, extracting the relevant information and turning them into knowledge, the most appropriate actions can be established for the continuous development of the company. In the competitive business environment, the rapid adjustment to the market requirements represents the only way the company can acquire advantages over its competitors. BI enables the usage of all the information the company holds, to proactively respond at the changes within the economic environment, being the guarantee of the business success. Concerning the future BI solutions, the users' request for more diversified, faster and more effective services is to be noticed. Companies will need solutions able to cope with future events. The users begin to demand the capability of real time analyses of the business data. The monthly and even weekly analyses will be not enough any longer. That's why Charles Nicholls, CEO of See Why, a British software company, said that business users do not want to wait to get information, and the information must be always available and never out of date.

The future means real time complex analyses, reporting, forecasting and data management. Accessing the relevant information in real time represents a critical point for assuring the success of the business. Its importance has grown along with the Internet development, with the growth of data sources number and their transmission speed. It is supposed that in the not too distant future companies will become dependent on real time business information, which will have to be obtained easily. Moreover, the future will belong to Web-based solutions, which will be able to provide information to a large number of users, both inside and outside the company. This is because BI has become a strategic initiative, and companies must share the information with an increasingly larger number of partners. In this sense, it is considered that BI will become part of business innovation. Sharing information with customers, providers, shareholders and other people interested in that business will increase loyalty and will give competitive advantages.

\section{References}

[GART06] Gartner Group, Press release, 
2006, www.gartner.com

[MICR04] Microsoft, Microsoft Solution for Business Intelligence, White paper, 2004, www.microsoft.com

[VELU06] M. Velicanu, I. Lungu, S. Iones$\mathrm{cu}$, Systems Development for Intelligent Business, in Social Science Research Network, 2006, www.ssrn.com

[VEMA07a] M. Velicanu, Gh. Matei, Databases versus Data Warehouses, Proceedings of the $8^{\text {th }}$ International Conference on Informatics in Economy, pp. 150-156, Academy of Economic Studies, ASE Publishing House, Bucharest, 2007

[VEMA07b] M. Velicanu, Gh. Matei, Aspecte comparative între baze de date şi depozite de date, Economic Computation and Economic Cybernetics Studies and Research, No. 2/2007, pp. 103-109, ASE Publishing House, Bucharest

[VEMA07c] M. Velicanu, Gh. Matei, Building a Data Warehouse Step by Step, Economy Informatics Review, No. 2 (42), 2007, pp. 83-89, Inforec Printing House, Bucharest [VEMA07d] M. Velicanu, Gh. Matei, Activităţi pentru realizarea depozitelor de date, Economic Computation and Economic Cybernetics Studies and Research, No. 3/2007, pp. 95-106, ASE Publishing House, Bucharest

[WIKI06] Wikipedia Encyclopedia, Business Intelligence, 2006, www.en.wikipedia.org 